\title{
PERAN PELATIHAN KETERAMPILAN MEDIK DAN KEPANITERAAN KLINIK TERHADAP KELULUSAN OSCE UKDI
}

\author{
Cecilia Felicia Chandra*, Fundhy Sinar Ikrar Prihatanto**, Nancy Margarita Rehatta** \\ * Mahasiswa Program Studi Pendidikan Dokter, Fakultas Kedokteran Universitas Airlangga Surabaya \\ ** Medical Education Research and Staff Development Unit, Fakultas Kedokteran Universitas Airlangga \\ Surabaya
}

\begin{abstract}
Background: One of the areas of competence expected from a doctor in Indonesia is clinical skills. It will be assessed in the National Objective Structured Clinical Examination (OSCE). In the Faculty of Medicine Airlangga University, there are four clinical skill modules in second to fifth semester. Afterward, students go to clinical posting to apply their clinical skill and practice profesionalism to real patients. The objective of this study is to measure the correlation between clinical skill examination score, educational environment, and Grade Point Average (GPA) during clinical posting and National OSCE's score.

Method: This study used cross sectional approach. Data were obtained from 143 national OSCE's participant. Primary data obtained from clinical posting's educational environment questionnaire. Secondary data consisted of five categorized scores from clinical skill examination during preclinic; clinical posting GPA; and National OSCE's scores. We conducted three different analyses: Spearman correlation test to measure the correlation of clinical skills examination scores to National OSCE's scores; Pearson correlation test to measure the correlation of clinical posting GPA to OSCE's scores; and correlation of clinical posting's questionnaire to OSCE's scores.

Results: Clinical skills examination score was weakly correlated with OSCE's score $(r=0,189, p<0,05)$. Clinical posting GPA was also correlated with OSCE's score $(r=0,417, p<0,001)$. But, there was no correlation of clinical posting's educational environment with OSCE's score ( $p>0,05)$.

Conclusions: There is a correlation between clinical skills examination scores and academic achievement during clinical posting with OSCE's score. But, there is no correlation between clinical posting's educational environment with OSCE's score.
\end{abstract}

Keywords: clinical skills, academic achievement, educational environment, national OSCE

\section{ABSTRAK}

Latar belakang: Salah satu area kompetensi yang diharapkan dari lulusan dokter di Indonesia adalah keterampilan. Kompetensi keterampilan akan dinilai dalam Objective Structured Clinical Examination (OSCE) Uji Kompetensi Dokter Indonesia (UKDI). Oleh karena itu, di Fakultas Kedokteran Universitas Airlangga (FK Unair) terdapat empat Modul Keterampilan medik yang diberikan sejak semester dua hingga lima. Setelah itu, mahasiswa kedokteran menjalani kepaniteraan klinik untuk melatih keterampilan dan profesionalisme kepada pasien sesungguhnya. Penelitian ini betujuan untuk mengukur korelasi antara nilai Modul Keterampilan Medik, Indeks Prestasi Kumulatif (IPK), dan educational environment kepaniteraan klinik dengan kelulusan OSCE UKDI.

Metode: Penelitian ini menggunakan rancangan cross sectional. Subyek penelitian adalah 143 peserta ujian OSCE UKDI. Data primer untuk menilai educational environment kepaniteraan klinik didapatkan dari kuesioner. Data sekunder terdiri dari kategorisasi nilai Modul Keterampilan Medik; IPK kepaniteraan klinik; dan nilai OSCE UKDI. Dilakukan tiga analisa korelasi : Korelasi Spearman untuk mengukur korelasi dari nilai Modul Keterampilan Medik dengan OSCE UKDI; Korelasi Pearson untuk mengukur korelasi IPK kepaniteraan klinik dengan nilai OSCE UKDI dan korelasi skor kuesioner dengan nilai OSCE UKDI

Korespondensi: felizchandra@live.com 
Hasil: Ditemukan korelasi lemah antara kategorisasi nilai Modul Keterampilan Medik dengan nilai OSCE UKDI $(r=0,189, p<0,05)$ dan antara IPK kepaniteraan klinik dengan nilai OSCE UKDI $(r=0,417 p<0,001)$. Untuk educational environment kepaniteraan klinik dengan nilai OSCE UKDI tidak ditemukan adanya korelasi $(p>$ $0,05)$

Kesimpulan: Terdapat korelasi antara nilai Modul Keterampilan Medik, dan IPK kepaniteraan klinik dengan nilai OSCE UKDI. Sedangkan, untuk educational environment kepaniteraan klinik dengan nilai OSCE UKDI tidak didapatkan korelasi.

Kata kunci: keterampilan medik, prestasi akademik, educational environment, OSCE nasional

\section{PENDAHULUAN}

Menurut SK Mendiknas No. 045/U/2002 dalam SKDI tahun 2006 kompetensi adalah 'seperangkat tindakan cerdas dan penuh tanggung jawab yang dimiliki seseorang sebagai syarat untuk dianggap mampu oleh masyarakat dalam melaksanakan tugas di bidang pekerjaan tertentu. ${ }^{1}$ Komponen-komponen kompetensi sendiri dapat dilihat dari kepribadian atau attitude, penguasaan ilmu atau knowledge, dan keterampilan atau skills yang menunjukkan pentingnya aplikasi dari pengetahuan atau knowledge. ${ }^{2}$ Kompetensi yang dicapai seorang dokter setelah melalui pelatihan keterampilan medik dan kepaniteraan klinik tentunya memerlukan suatu ujian untuk pengukurannya apakah sudah sesuai dengan standar atau belum. Oleh karena itu, diperlukan competency based assessment. Di Indonesia sejak tahun 2013, menurut Surat Edaran Dirjen Pendidikan Tinggi Kementerian Pendidikan dan Kebudayaan no 88/E/ DT/2013, Uji Kompetensi Dokter Indonesia (UKDI) digunakan sebagai exit exam meliputi Computer Based Testing (CBT) dengan pertanyaan pilihan ganda dan Objective Structured Clinical Examination (OSCE) untuk menguji attitude, knowledge, dan skills. ${ }^{3}$

Salah satu area kompetensi yang diharapkan dari lulusan dokter di Indonesia adalah keterampilan. ${ }^{4}$ Pada setiap keterampilan klinis ditetapkan tingkat kemampuan yang harus dicapai di akhir pendidikan dokter dengan menggunakan Piramid Miller. Sesuai dengan Piramid Miller terdapat 4 tingkat kemampuan yang harus dicapai: Tingkat kemampuan 1 (knows): mengetahui dan menjelaskan; Tingkat kemampuan 2 (knows how): pernah melihat atau didemonstrasikan; Tingkat kemampuan 3 (shows): pernah melakukan atau pernah menerapkan di bawah supervisi; Tingkat kemampuan 4 (does): mampu melakukan secara mandiri. ${ }^{5}$ Tingkat keterampilan yang perlu dicapai saat lulus dokter adalah 4A. ${ }^{4}$ Untuk mencapai kompetensi keterampilan klinis, pada tahap Sarjana Kedokteran di FK Unair yang terbagi dalam 3 sub-program dengan terdapat 4 Modul Keterampilan Medik yang telah diberikan sejak sub program I semester 2 hingga sub-program II semester $5 .{ }^{6}$

Pelatihan menggunakan fasilitas simulasi lingkungan klinik dengan manekin atau pasien terstandarisasi. ${ }^{7}$ Penggunaan simulator berdasarkan pada keuntungan dimana alat-alat tersebut dapat tersedia di setiap waktu dan dapat memaparkan berbagai kondisi klinis sesuai permintaan. ${ }^{8}$ Penelitian di salah satu fakultas kedokteran di Indonesia menunjukkan 91,5\% mahasiswa membutuhkan pelatihan keterampilan medik sejak awal pada setiap semester. Beberapa alasan dari kebutuhan mahasiswa kedokteran yang menjadi subyek dalam penelitian tersebut adalah memudahkan untuk menguasai bahan, agar terbiasa dengan suasana praktik, mengaitkan teori dengan praktik, mengasah keterampilan medis, dan memudahkan menghadapi

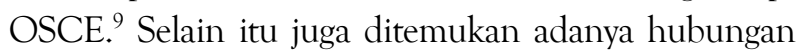
nilai ujian OSCE pada mahasiswa kedokteran tahun ke-2 dengan USMLE tahap $2 .{ }^{10}$

Untuk melatih kompetensi knowledge dan attitude lebih baik di samping skills maka diperlukan tahap Kepaniteraan Klinik yaitu semester 8 sampai dengan semester 11 untuk penerapan ketiga komponen kompetensi itu. Selama fase klinik, Dokter Muda belajar dalam situasi klinik seperti pelayanan kesehatan primer, sekunder (rumah sakit daerah), dan/atau tersier (rumah sakit universitas). Selama rotasi di berbagai macam 
departemen klinik Dokter Muda berhubungan dengan pasien rawat jalan dan pasien rawat inap. Tetapi fase klinik ini biasanya lebih tidak terstruktur dibandingkan tahap Sarjana Kedokteran dan memiliki keterbatasan tertentu. ${ }^{11}$ Milieu atau educational environment selama kepaniteraan klinik dapat mempengaruhi prestasi siswa. Penelitian Wayne, et al. menunjukkan hubungan yang signifikan antara tiga subskala educational environmentdan prestasi akademik yang dilihat dari skor United States Medical License Examination (USMLE) Tahap $1 .{ }^{12}$ Untuk mengevaluasi lingkungan belajar dokter junior di rumah sakit dikembangkan Postgraduate Hospital Educational Environment Measure (PHEEM) yaitu kuesioner berisi 40 pertanyaan yang terbagi dalam 3 subskala yaitu Perception of Autonomy, Perception of Teaching, and Perception of Social Support yang dikembangkan di United Kingdom oleh Roff tahun 2005. ${ }^{13}$

Ukuran kemampuan mahasiswa dalam menyelesaikan sebuah kurikulum dan predikat kelulusannya dinyatakan dengan Indeks Prestasi Kumulatif (IPK). Sehingga mahasiswa yang telah dinyatakan lulus dapat dikatakan memiliki kompetensi sebagai seorang dokter dengan indikasi semakin tinggi IPK semakin tinggi pula kualitas individu sebagai seorang dokter. ${ }^{14}$ Studi sebelumnya mengenai IPK dengan uji standar kompetensi kedokteran pernah dilakukan dan terdapat hubungan antara IPK mahasiswa tahun ketiga dengan USMLE tahap 1.15

Oleh karena itu, peneliti juga ingin mengetahui hubungan nilai Modul Keterampilan Medik dan prestasi akademik pada tahap Kepaniteraan Klinik dengan kelulusan OSCE UKDI pada mahasiswa kedokteran lulusan FK Unair. Peneliti juga ingin meneliti tentang hubungan educational environment selama kepaniteraan klinik dengan kelulusan OSCE UKDI pada mahasiswa kedokteran lulusan FK Unair dan hubungan prestasi akademik kepaniteraan klinik dengan kelulusan OSCE UKDI.

\section{METODE}

Penelitian ini menggunakan metode observasional analitik dengan rancangan penelitian cross sectional. Total sampling dilakukan pada subyek penelitian yaitu peserta ujian OSCE UKDI. Penelitian ini kami laksanakan dari bulan November 2013 sampai akhir Maret 2014. Kriteria inklusi adalah peserta ujian OSCE UKDI periode November 2013. Untuk kriteria eksklusi adalah peserta ujian OSCE UKDI yang tidak lulus dua kali atau lebih.

Dari 158 responden didapatkan 155 subyek penelitian yang bersedia mengikuti penelitian. Dari 155 subyek penelitian, 8 subyek dikeluarkan dari analisis penelitian karena data tidak lengkap, 4 subyek dikeluarkan karena memiliki nilai yang ekstrim sehingga total akhir terdapat 143 subyek penelitian.

Penilaian educational environment di kepaniteraan klinik menggunakan data primer yang diperoleh dari kuesioner PHEEM. Penelitian ini menggunakan data sekunder yang diperoleh dari: 1) Nilai Modul Keterampilan Medik; 2) IPK selama kepaniteraan klinik yang menunjukkan prestasi akademik; 3) Hasil ujian OSCE UKDI. Untuk kuesioner PHEEM digunakan skor tiap subskala (Perception of Autonomy, Perception of Teaching, and Perception of Social Support) dan skor total kuesioner yang dimasukkan dalam uji korelasi. Sedangkan untuk nilai Modul Keterampilan Medik terdapat 4 nilai dari semester 2 hingga semester 5 . Nilai 4 Modul Keterampilan Medik dikategorikan dengan tingkatan sebagai berikut: 4 nilai $\mathrm{B}=1 ; 3$ nilai $\mathrm{B}=2 ; 2$ nilai $\mathrm{B}=3 ; 1$ nilai $\mathrm{B}=4$; Tidak ada nilai $B=5$. Lima kategorisasi tersebut yang dimasukkan dalam uji korelasi.

Uji distribusi data menggunakan uji Kolmogorov-Smirnov karena sampel yang besar (lebih dari 50). Uji Kolmogorov-Smirnov dilakukan untuk variabel nilai OSCE UKDI, IPK kepaniteraan klinik, skor tiap subskala PHEEM, dan skor total PHEEM. Untuk melihat distribusi kategorisasi nilai Modul Keterampilan Medik digunakan pie chart. Dalam penelitian ini digunakan 2 macam uji korelasi bivariat yaitu Korelasi Spearman dan Korelasi Pearson. Untuk mengukur korelasi antara variabel bebas dan terikat pada data ordinal yaitu nilai Modul Keterampilan Medik dengan OSCE UKDI digunakan Korelasi Spearman. Korelasi Pearson digunakan untuk mengukur korelasi antara variabel interval yang berdistribusi normal yaitu IPK kepaniteraan klinik dengan nilai OSCE UKDI dan korelasi skor kuesioner dengan nilai OSCE UKDI. 


\section{HASIL DAN PEMBAHASAN}

Dari uji normalitas penelitian variabel didapatkan $\mathrm{p}>0,05$ untuk variabel nilai OSCE UKDI, IPK kepaniteraan klinik, skor tiap subskala PHEEM, dan skor total PHEEM sehingga dapat disimpulkan distribusinya normal. Kategorisasi nilai Modul Keterampilan Medik menunjukkan tidak ada yang masuk kategori 1 (4 nilai B). Tampak kategori $4(n=48)$ dan $5(n=68)$ memiliki frekuensi yang banyak dibanding kategori $2(n=11)$ dan $3(n=16)$.

Dari uji Korelasi Spearman diperoleh nilai $\mathrm{p}<0,05$ yang menunjukkan korelasi bermakna antara nilai Modul Keterampilan Medik dan kelulusan OSCE UKDI. Nilai koefisien Korelasi Spearman sebesar 0,189 menunjukkan bahwa arah korelasi positif dengan kekuatan korelasi rendah. Dari uji korelasi Pearson, diperoleh nilai $p<0,001$ untuk korelasi antara prestasi akademik selama kepaniteraan klinik dan kelulusan OSCE UKDI ( $\mathrm{r}=$ 0,417) menunjukkan korelasi positif. Sedangkan untuk variabel lain, nilai $\mathrm{p}>0,001$ menunjukkan bahwa tidak ada korelasi antara educational environment kepaniteraan klinik dilihat dari berbagai subskala kuesioner dengan kelulusan OSCE UKDI (Tabel 1). Nilai p berturut-turut untuk subskala perception of autonomy $\mathrm{p}=0,067$, perception of teaching $\mathrm{p}=0,532$, dan perception of social support $\mathrm{p}=$ 0,96 . Begitu juga dengan skor total kuesioner didapat nilai $\mathrm{p}=0,327$.

Tabel 1. Uji Korelasi IPK kepaniteraan klinik, subskala kuesioner PHEEM, dan skor total kuesioner PHEEM dengan nilai OSCE UKDI

\begin{tabular}{ll} 
Korelasi & $\mathbf{R}$ \\
\hline IPK kepaniteraan klinik terhadap nilai OSCE I JKDI & $0,417^{* *}$ \\
Perception of Autonomy terhadap nilai OSCE UKDI & $-0,154$ \\
Perception of Teaching terhadap nilai OSCE UKDI & $-0,053$ \\
Perception of Social support terhadap nilai OSCE UKDI & $-0,004$ \\
Skor total PHEEM terhadap nilai OSCE UKDI & $-0,083$ \\
\hline
\end{tabular}

${ }^{* * *} p<0,001$

Korelasi antara nilai Modul Keterampilan Medik dengan kelulusan OSCE UKDI sejalan dengan penelitian di Amerika tentang korelasi antara nilai OSCE pada mahasiswa kedokteran tahun kedua dengan nilai USMLE tahap 2 yang menunjukkan koefisien korelasi yang lebih kuat yaitu 0,395 ( $p<0,001) .{ }^{10}$ Perbedaan yang didapat pada kedua penelitian tersebut adalah USMLE tahap 2 untuk menilai kompetensi klinis hanya diuji menggunakan pertanyaan multiple choice dan belum diterapkan sistem OSCE saat penelitian itu berlangsung. Sedangkan dalam penelitian ini kompetensi klinik sudah diuji dengan ujian OSCE. Penelitian lain yang hasilnya juga sejalan dengan penelitian ini menemukan kekuatan korelasi sedang yaitu 0,58 antara nilai Clinical Performance Examination (CPE) pada tahun kedua dengan nilai CPE pada tahun keempat sebelum kelulusan. CPE pada penelitian tersebut menggunakan metode OSCE. ${ }^{16}$ Kedua penilitian ini memiliki kemiripan dimana penilaian kompetensi klinik menggunakan simulasi kasus dan pasien terstandarisasi telah dimulai sejak tahun pertama dan kedua.

Korelasi antara prestasi akademik pada kepaniteraan klinik dengan kelulusan OSCE UKDI pada penelitian ini sejalan dengan penelitian di salah satu fakultas kedokteran di Indonesia dimana IPK pada pendidikan profesi memiliki korelasi dengan skor UKDI yang menunjukkan koefisien korelasi 0,522 dan $p<0,001{ }^{14}$ Korelasi antara educational environment kepaniteraan klinik dengan nilai OSCE UKDI pada penelitiaan ini berbeda dengan penelitian Mayya \& Roff yang menemukan perbedaan jelas antara persepsi lingkungan belajar bagi siswa berprestasi (academic achievers) dan tidak berprestasi (under achievers). Under achievers secara signifikan memberikan skor total kuesioner Dundee Ready Educatonal Environment Measure lebih rendah daripada academic achievers. ${ }^{17}$ Penelitian ini juga berbeda dengan Wayne, et 
al. yang menunjukkan hubungan yang signifikan antara tiga subskala educational environment dan prestasi akademik yang dilihat dari skor USMLE Tahap $1 .{ }^{12}$ Pada penelitian lain di Jepang didapatkan hasil yang sejalan dengan penelitian ini dimana tidak ada korelasi antara nilai National Medical Licensure Examination (NMLE) dengan educational environment $(\mathrm{p}=0,063) .{ }^{18}$

Keterbatasan penelitian ini adalah penggunaan kuesioner PHEEM untuk menilai lingkungan belajar kepaniteraan klinik secara keseluruhan bukan dinilai setiap menjalani kepaniteraan di departemen tertentu sehingga bisa jadi hasil yang didapat kurang spesifik. Sebaiknya untuk penilaian educational environment kepaniteraan klinik dilakukan dengan lebih spesifik misalnya tiap departemen tidak digeneralisasikan dalam satu kuesioner.

\section{KESIMPULAN}

Terdapat hubungan antara nilai Modul Keterampilan Medik dengan kelulusan OSCE UKDI dan prestasi akademik kepaniteraan klinik dengan kelulusan OSCE. Tidak didapatkan korelasi baik dari masing-masing subskala maupun skor total kuesioner PHEEM yang menggambarkan educational environment kepaniteraan klinik dengan kelulusan OSCE UKDI. Jadi, dapat disimpulkan nilai Modul Keterampilan Medik dan prestasi akademik kepaniteraan klinik pada penelitian ini dapat menggambarkan kelulusan OSCE. Educational environment pada penelitian ini tidak dapat menggambarkan kelulusaan OSCE. Keterbatasan pada pengisian kuesioner PHEEM untuk menilai educational environment adalah penilaian dilakukan sejak keseluruhan bukan setiap menjalani kepaniteraan di departemen tertentu.

\section{DAFTAR PUSTAKA}

1. Konsil Kedokteran Indonesia. Standar Kompetensi Dokter. Jakarta: Konsil Kedokteran Indonesia; 2006.

2. Carraccio C, Wolfsthal SD, Englander R, Ferentz K, Martin C. Shifting paradigms: from Flexner to competencies. Acad Med. 2002;77(5):361-7.

3. Direktorat Jenderal Pendidikan Tinggi Kementerian Pendidikan dan Kebudayaan. Health Professional Education Quality Direktorat Jenderal Pendidikan Tinggi [Internet]. 2013 [cited 2013 Jul 3]. Available from: http://hpeq.dikti.go.id/v2/index. php? option
$=$ com_content $\&$ view $=$ article $\&$ id $=6:$ pengumuman-se-ukdi-sebagai-exit-exam $\&$ catid $=13$ : whats-new\& Itemid=196

4. Konsil Kedokteran Indonesia. Standar Kompetensi Dokter Indonesia. 2nd ed. Jakarta: Konsil Kedokteran Indonesia; 2012.

5. Miller GE. The assessment of clinical skills/ competence/ performance. Acad Med. 1990; 65(9): 563-7.

6. Tim Penyusun Pedoman Pendidikan Program Pendidikan Sarjana dan Profesi Fakultas Kedokteran Universitas Airlangga, 2011. Panduan Pendidikan Program Pendidikan Sarjana dan Profesi Fakultas Kedokteran Universitas Airlangga. Surabaya: Fakultas Kedokteran Universitas Airlangga.

7. Weller JM, Nestel D, Marshall SD, Brooks PM, Conn JJ. Simulation in clinical teaching and learning. Med J Aust [Internet]. 2012 May 21 [cited 2014 Oct 27]; 196(9):1-5. Available from: http://www.ncbi .nlm.nih.gov/pubmed/22621154

8. Scalese RJ, Obeso VT, Issenberg SB. Simulation technology for skills training and competency assessment in medical education. J Gen Intern Med [Internet]. 2008 Jan [cited 2014 Jul 21];23(1):46-9. Available from: http://www.pubmedcentral.nih.gov/ articlerender.fcgi?artid $=2150630 \&$ tool= pmcentrez $\&$ rendertype $=$ abstract

9. Sandika E. Identifikasi kebutuhan mahasiswa kedokteran terhadap pelatihan keterampilan klinik di setiap jenjang pendidikan sarjana [dissertation]. Semarang (Indonesia): Universitas Diponegoro; 2012.

10. Simon SR, Bui A, Day S, Berti D, Volkan K. The relationship between second-year medical students' OSCE scores and USMLE Step 2 scores. J Eval Clin Pract. 2007;13(6):901-5.

11. Widyandana. Integrating pre-clinical skills training in skills laboratory and primary health care centers to prepare medical students for their clerkship. Yogyakarta: Kelompok Penerbit Tiara Wacana; 2011.

12. Wayne SJ, Fortner SA, Kitzes JA, Timm C, Kalishman S. Cause or effect? The relationship between student perception of the medical school learning environment and academic performance on USMLE Step 1. Med Teach [Internet]. 2013 May [cited 2015 Jan 11];35(5):376-80. Available from: http:// www.ncbi.nlm.nih.gov/pubmed/23444883

13. Aspegren K, Bastholt L, Bested KM, Bonnesen T, Ejlersen E, Fog I, et al. Validation of the PHEEM instrument in a Danish hospital setting. Med Teach. 2007;29:504-6.

14. Pramana SW. Hubungan antara Indeks Prestasi Kumulatif dengan nilai UKDI pada Program Pendidikan Dokter/ : Studi Kasus FK UNDIP 
[Internet]. Semarang; 2011 [cited 2013 Jul 10]. Available from: http://eprints.undip.ac.id/37248/1/ Salvandega.pdf

15. Fields SA, Morris C, Toffler WL, Keenan EJ. Early identification of students at risk for poor academic performance in clinical clerkships. Acad Med. 2000;75(10):78-80.

16. Klamen DL, Borgia PT. Can students' scores on preclerkship clinical performance examinations predict that they will fail a senior clinical performance examination? Acad Med [Internet]. 2011 Apr [cited 2015 Jan 11];86(4):516-20. Available from: http:// www.ncbi.nlm.nih.gov/pubmed/21346501
17. Mayya SS, Roff S. Students' perceptions of educational environment: A comparison of academic achievers and under-achievers at Kasturba Medical College, India. Educ Heal [Internet]. 2004 Nov [cited 2015 Jan 11];17(3):280-91. Available from: http:// www.ncbi.nlm.nih.gov/pubmed/15848815

18. Tokuda Y, Goto E, Otaki J, Jacobs J, Omata F, Obara $\mathrm{H}$, et al. Undergraduate educational environment, perceived preparedness for postgraduate clinical training, and pass rate on the National Medical Licensure Examination in Japan. BMC Med Educ. 2010;10(35):1-9. 